\title{
Pre-pregnancy BMl, gestational weight gain and risk of preeclampsia: a birth cohort study in Lanzhou, China
}

\author{
Yawen Shao', Jie Qiu', Huang Huang², Baohong Mao', Wei Dai', Xiaochun He', Hongmei Cui', Xiaojuan Lin', \\ Ling Lv', Dennis Wang², Zhongfeng Tang ${ }^{1}$, Sijuan Xu', Nan Zhao², Min Zhou', Xiaoying Xu', Weitao Qiu', \\ Qing Liu ${ }^{1 *+}$ and Yawei Zhang ${ }^{2,3^{*}+}$
}

\begin{abstract}
Background: To evaluate the independent and joint effects of maternal pre-pregnancy BMI and gestational weight gain (GWG) on the risk of preeclampsia and its subtypes.

Methods: A birth cohort study was conducted from 2010 to 2012 in Lanzhou, China. Three hundred fourty seven pregnant women with preeclampsia and 9516 normotensive women at Gansu Provincial Maternity and Child Care Hospital were included in the present study. Unconditional logistic regression models were used to evaluate the associations between pre-pregnancy BMI, GWG, and risk of preeclampsia and its subtypes.

Results: Compared to women with normal pre-pregnancy BMl, those who were overweight/obese had an increased risk of preeclampsia ( $\mathrm{OR}=1.81 ; 95 \% \mathrm{Cl}$ : 1.37-2.39). Women with excessive GWG had an increased risk of preeclampsia ( $\mathrm{OR}=2.28 ; 95 \% \mathrm{Cl}$ : 1.70-3.05) compared to women with adequate GWG. The observed increased risk was similar for mild-, severe- and late-onset preeclampsia. No association was found for early-onset preeclampsia. Overweight/obese women with excessive GWG had the highest risk of developing preeclampsia compared to normal weight women with no excessive weight gain ( $\mathrm{OR}=3.78$; 95\% Cl: 2.65-5.41).
\end{abstract}

Conclusions: Our results suggested that pre-pregnancy BMI and GWG are independent risk factors for preeclampsia and that the risk might vary by preeclampsia subtypes. Our study also proposed a potential synergistic effect of pre-pregnancy BMI and GWG that warrants further investigation.

Keywords: Pre-pregnancy BMl, Gestational weight gain, Preeclampsia, China, Birth cohort

\section{Background}

Preeclampsia is defined as the development of hypertension and proteinuria after 20 weeks of gestation [1]. It affects up to $8 \%$ of all pregnancies worldwide and increases morbidity and mortality rates among both mothers and infants $[2,3]$. Preeclampsia is the leading cause of prematurity and fetal growth restriction $[4,5]$. The mortality rate among babies born to mothers with preeclampsia is five times higher than that among babies

\footnotetext{
* Correspondence: 2305470816@qq.com; yawei.zhang@yale.edu

${ }^{\dagger}$ Equal contributors

'Gansu Provincial Maternity and Child Care Hospital, 143 North Road, Qilihe District, Lanzhou, Gansu Province 730050, China

${ }^{2}$ Yale University School of Public Health, 60 College Street, New Haven, CT 06520, USA
}

Full list of author information is available at the end of the article born to healthy mothers [6]. Preeclampsia is also the second leading cause of pregnancy-related intensive care unit admissions after obstetric hemorrhage [7]. Furthermore, preeclampsia is associated with an elevated risk of cardiovascular disease later in life $[8,9]$.

Given the known and potential adverse consequences of preeclampsia, an understanding of the risk factors of this condition is warranted. A wide range of pregnancyspecific characteristics (e.g. parity, placental factors, multi-fetal gestation, and excessive weight gain during pregnancy) and pre-existing maternal features (e.g. age, race, pre-pregnancy overweight or obesity, pre-pregnancy diabetes, chronic hypertension etc.) are considered to be associated with preeclampsia [10]. Pre-pregnancy BMI and gestational weight gain (GWG) are two modifiable 
risk factors [11-13]. Both pre-pregnancy BMI and GWG may increase oxidative stress levels, stimulate a systemic inflammatory response, and accelerate damage to vascular endothelial cells, resulting in preeclampsia [14, 15]. Studies from different populations have consistently reported that elevated pre-pregnancy BMI is associated with an increased risk of preeclampsia [16-38]. However, the relationship between GWG and preeclampsia is still inconclusive, with some studies suggesting a positive association [9, 30, 39-49] and others reporting no association [11, 21, 50, 51]. Few studies have examined the relationship between prepregnancy BMI, GWG and the risk of preeclampsia by different subtypes [14, 30, 43, 52, 53]. Even fewer studies have investigated the joint effect of pre-pregnancy BMI and GWG on preeclampsia and its subtypes. Here, we analyzed data from a birth cohort study conducted in Lanzhou, China $[54,55]$ to evaluate the independent and joint effects of maternal pre-pregnancy BMI and GWG on the risk of preeclampsia and its various subtypes.

\section{Methods}

A birth cohort study was carried out from 2010 to 2012 at Gansu Provincial Maternity and Child Care Hospital, the largest hospital of its kind in Lanzhou, China. Eligible study participants were pregnant women who came to the hospital for delivery with gestational age $\geq$ 20 weeks, who had no history of mental illness, and who were 18 years or older. A total of 14,359 eligible women were identified and invited to participate. Of those, 3712 refused to participate and 105 did not complete inperson interviews, yielding 10,542 (73.4\%) women with completed interviews. Upon obtaining written consent, a standardized and structured questionnaire was used to collect information on demographic factors, reproductive and medical history, smoking and alcohol consumption, occupational and residential history, physical activity, and diet. Information on pregnancy complications and birth outcomes were abstracted from medical records. After excluding women with pre-existing chronic hypertension before pregnancy and missing values of pre-pregnancy BMI or GWG, the final sample size was 9863 . Among these women, 347 were diagnosed with preeclampsia. All study procedures were approved by the Human Investigation Committees at the Gansu Provincial Maternity and Child Care Hospital and Yale University. Additional detailed information on the cohort has previously been published $[54,55]$.

Preeclampsia was defined as hypertension (two separate blood pressure readings $\geq 140 / 90 \mathrm{mmHg}$ taken at least $6 \mathrm{~h}$ apart) and proteinuria ( $\geq 1+$ on dipstick test in two urine samples or $\geq 300 \mathrm{mg}$ of protein in a $24 \mathrm{~h}$ urine sample) after 20 weeks of gestation. Preeclampsia was further subcategorized as mild preeclampsia (M-PE) and severe preeclampsia (S-PE), as well as early-onset preeclampsia (EOPE) and late-onset (LOPE) [54]. M-PE was defined as raised blood pressure $(\geq 140 / 90 \mathrm{mmHg}$ and $<160 / 110 \mathrm{mmHg}$ ) and proteinuria $(\geq 1+$ and $<2+$ on dipstick test in two urine samples) without symptoms of severity. S-PE was defined as raised blood pressure $(\geq$ $160 / 110 \mathrm{mmHg}$ ) and proteinuria ( $\geq 2+$ on dipstick test in two urine samples) with additional symptoms of severity such as headache, blurred vision, epigastric pain, decreased urine output, and decreased or absent fetal kick. Women with EOPE had preeclampsia before 34 weeks of gestation, while those with LOPE had preeclampsia at or after 34 weeks of gestation.

Pre-pregnancy weight was self-reported during the first prenatal care visit. Pre-pregnancy BMI was calculated as weight $(\mathrm{kg})$ divided by the square of height $(\mathrm{m})$, and then subcategorized as underweight $(\mathrm{BMI}<18.5 \mathrm{~kg} /$ $\left.\mathrm{m}^{2}\right)$, normal weight $\left(18.5 \mathrm{~kg} / \mathrm{m}^{2} \leq \mathrm{BMI}<24 \mathrm{~kg} / \mathrm{m}^{2}\right)$, and overweight $\left(B M I \geq 24 \mathrm{~kg} / \mathrm{m}^{2}\right)$ groups. Since East Asians have a higher body fat percentage than Caucasians [56], the BMI cutoffs for overweight and obesity differ between Eastern and Western populations. The standards used in this study were established by the Working Group of Obesity in China [57]. As only a small number of women were obese, overweight and obese women were combined to increase statistical power.

Gestational weight gain (GWG) in $\mathrm{kg}$ was calculated by subtracting pre-pregnancy weight from maternal weight at delivery. Since there were no official recommendations specific to the Chinese population, GWG was categorized based on the US Institute of Medicine (IOM) GWG Guidelines 2009 [58]. Adequate weight gain was defined as $12.5-18.0 \mathrm{~kg}, 11.5-16.0 \mathrm{~kg}$, and 7.0$11.5 \mathrm{~kg}$ for underweight, normal weight, and overweight women, respectively.

Differences in selected characteristics between women with preeclampsia and normotensive women were evaluated using Chi-square tests or Fisher's exact tests if necessary. Unconditional logistic regression was used to determine odds ratios (OR) and 95\% confidence intervals (CI) for the associations between pre-pregnancy BMI, GWG, and the risk of preeclampsia and its subtypes. Confounding factors including maternal age, maternal employment during pregnancy, monthly household income, maternal education level, parity, twin status, newborn gender, and family history of hypertension were adjusted for in the unconditional logistic regression models. All statistical tests were two-sided. Analyses were performed using SAS 9.3 (SAS Institute, Inc., Cary, NC, USA).

\section{Results}

A total of 9863 women were included in the final analysis of which 347 (3.52\%) were diagnosed with preeclampsia. Among those with preeclampsia, 206 (59.4\%) had S-PE and 
Table 1 Distribution of Selected Characteristics of the Study Population

\begin{tabular}{|c|c|c|c|c|c|}
\hline \multirow[t]{2}{*}{ Characteristics } & \multicolumn{2}{|c|}{ All participants } & \multicolumn{2}{|c|}{ Preeclampsia } & \multirow[t]{2}{*}{$P$-value ${ }^{a}$} \\
\hline & $n$ & (\%) & $n$ & $(\%)$ & \\
\hline All & 9863 & 100 & 347 & 3.5 & \\
\hline Maternal age & & & & & $<0.001$ \\
\hline$<25 y$ & 4780 & 48.5 & 131 & 2.7 & \\
\hline $25-29 y$ & 1530 & 15.5 & 52 & 3.4 & \\
\hline$\geq 30 y$ & 3553 & 36.0 & 164 & 4.6 & \\
\hline
\end{tabular}

Employment status

$\begin{array}{lllll}\text { Yes } & 5180 & 52.5 & 151 & 2.9 \\ \text { Not during pregnancy } & 1524 & 15.5 & 56 & 3.7 \\ \text { Never } & 3159 & 32.0 & 140 & 4.4\end{array}$

Monthly income (RMB)

$<3000$

$\geq 3000$

4995

3998

50.6

40.5

Education level

$\geq$ college
$<$ college
Parity

3734

5878

37.9

$$
\begin{aligned}
& 37.9 \\
& 59.6
\end{aligned}
$$$$
250
$$

Multifarious

Primiparous

$$
2679
$$$$
7184
$$

Newborn gender

Male
Female
Twin
Yes
No

Family history of hypertension

Yes

No

Pre-pregnancy BMI ${ }^{\mathrm{b}}$

Normal weight

Underweight

6699
2104

Overweight

1060

5200

4633

27.2

27.2

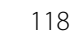

229

3.2

Gestational weight gain(GWG)

$\begin{array}{lllll}\text { Inadequate } & 1323 & 13.4 & 33 & 2.5 \\ \text { Adequate } & 3279 & 33.2 & 62 & 1.9 \\ \text { Excessive } & 5261 & 53.3 & 252 & 4.8\end{array}$

Maternal diabetes

$\begin{array}{lllll}\text { Yes } & 97 & 1.0 & 7 & 7.2 \\ \text { No } & 9766 & 99.0 & 340 & 3.5\end{array}$

Smoking (passive and active) during pregnancy

$\begin{array}{lllll}\text { Yes } & 1928 & 19.5 & 75 & 3.9 \\ \text { No } & 7935 & 80.5 & 272 & 3.4\end{array}$

Table 1 Distribution of Selected Characteristics of the Study

\begin{tabular}{|c|c|c|c|c|c|}
\hline \multirow[t]{2}{*}{ Characteristics } & \multicolumn{2}{|c|}{ All participants } & \multicolumn{2}{|c|}{ Preeclampsia } & \multirow[t]{2}{*}{$P$-value ${ }^{a}$} \\
\hline & $\mathrm{n}$ & (\%) & $n$ & $(\%)$ & \\
\hline \multicolumn{5}{|c|}{ Alcohol consumption during pregnancy } & $1^{*}$ \\
\hline Yes & 17 & 0.2 & 0 & & \\
\hline No & 9846 & 99.8 & 347 & 3.5 & \\
\hline \multicolumn{5}{|c|}{ Physical activity during pregnancy } & 0.796 \\
\hline Yes & 8250 & 83.6 & 292 & 3.5 & \\
\hline No & 1613 & 16.4 & 55 & 3.4 & \\
\hline
\end{tabular}
Population (Continued)

${ }^{a}$ The analysis did not account for missing data. For variable Monthly income (RMB), data was missing for 870 participants, for variable Education level, data was missing for 251 participants, for variable Newborn gender, data was missing for 30 participants

${ }^{\mathrm{b}}$ Weight $(\mathrm{kg}) /$ height $^{2}\left(\mathrm{~m}^{2}\right)$

$<0.0001 \quad$ *Fisher's exact test, for all other variables Chi-square test

141 (40.6\%) had M-PE, while 304 (87.6\%) had LOPE, and $43(12.4 \%)$ had EOPE. The prevalence of pre-pregnancy underweight, normal weight and overweight (including obesity) were $21.33 \%, 67.92 \%$, and $10.75 \%$, respectively.

Table 1 shows general characteristics of the study population. Compared to normotensive women, women with preeclampsia were more likely to be older, unemployed, less educated, multiparous, pregnant with a female fetus or multiple fetuses, had lower monthly household income and a family history of hypertension. The distributions of maternal diabetes, smoking (active and passive) during pregnancy, alcohol consumption during pregnancy, and physical activity during pregnancy were similar between women with and without preeclampsia.

Pre-pregnancy overweight or obesity was associated $<0.0001$ with an increased risk of preeclampsia $(\mathrm{OR}=1.81,95 \% \mathrm{CI}$ : 1.37-2.39), M-PE ( $\mathrm{OR}=1.76,95 \% \mathrm{CI}: 1.14-2.71)$, S-PE $(\mathrm{OR}=1.79,95 \% \mathrm{CI}: 1.26-2.54)$, and LOPE $(\mathrm{OR}=1.79$, 95\%CI: 1.33-2.41) compared to normal weight (Table 2). Underweight was associated with a reduced risk of S-PE (OR $=0.60,95 \% \mathrm{CI}: \quad 0.38-0.95)$ compared to normal weight. Compared to women with adequate GWG, women with excessive GWG had more than a two-fold increased risk of preeclampsia $(\mathrm{OR}=2.28,95 \% \mathrm{CI}$ : 1.70 3.05), M-PE (OR = 2.79, 95\%CI: 1.74-4.47), S-PE (OR = 2.03, 95\%CI: $1.41-2.92)$, and LOPE $(\mathrm{OR}=2.53,95 \% \mathrm{CI}$ : 1.84-3.48). Inadequate GWG was not associated with the risk of preeclampsia and its subtypes. We further analyzed GWG using the quartiles of GWG among normotensive $0.085^{*}$ women. Compared to the lowest GWG quartile, the highest quartile was associated with an increased risk of preeclampsia $(\mathrm{OR}=2.59,95 \% \mathrm{CI}$ : $1.90-3.53)$, M-PE $(\mathrm{OR}=3.55,95 \% \mathrm{CI}: 2.13-5.92), \mathrm{S}-\mathrm{PE}(\mathrm{OR}=2.17,95 \% \mathrm{CI}$ : 1.48-3.19), and LOPE (OR $=2.95,95 \% \mathrm{CI}: 2.10-4.13)$. The second highest GWG quartile was associated with an increased risk of preeclampsia $(\mathrm{OR}=1.66,95 \% \mathrm{CI}$ : 1.18-2.33), $\mathrm{M}-\mathrm{PE}(\mathrm{OR}=2.17,95 \% \mathrm{CI}: 1.25-3.78)$, and 


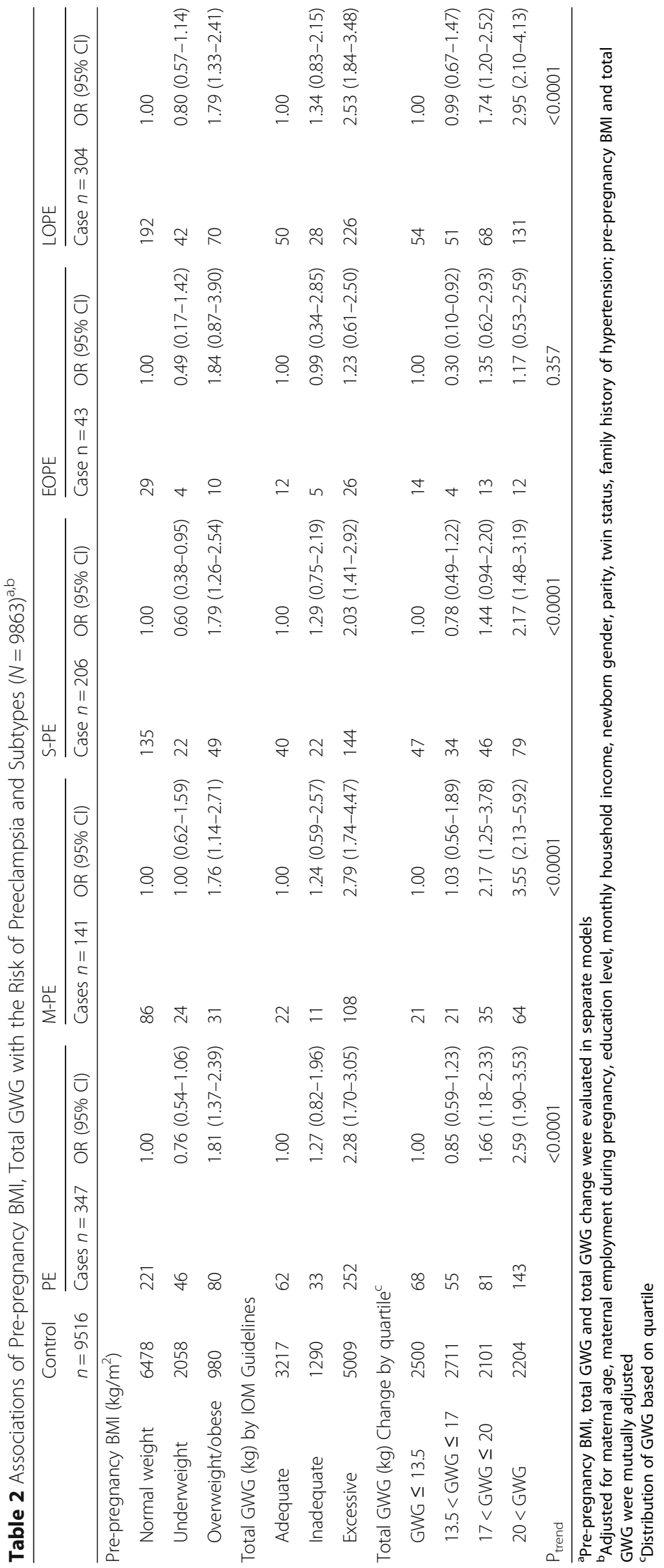


LOPE $(\mathrm{OR}=1.74,95 \% \mathrm{CI}: 1.20-2.52)$. A significant $\mathrm{P}$ trend was observed for preeclampsia, M-PE, S-PE, and LOPE. We also found a decreased risk of EOPE associated with the second GWG quartile (OR $=0.30$, 95\%CI: 0.10 $0.92)$, but this association was based on four exposed cases.

Joint effects between pre-pregnancy BMI and GWG on the risk of preeclampsia and its subtypes are presented in Table 3. Women with both pre-pregnancy overweight (including obesity) and excessive GWG had the highest risk of preeclampsia $(\mathrm{OR}=3.78,95 \% \mathrm{CI}$ : 2.65-5.41), M-PE $(\mathrm{OR}=4.82,95 \% \mathrm{CI}: 2.71-8.59)$, S-PE $(\mathrm{OR}=3.22$, 95\%CI: $2.06-5.03)$, and LOPE $(\mathrm{OR}=4.11$, 95\%CI: 2.81-6.03), although there was no statistically significant interaction between pre-pregnancy BMI and GWG $\left(P_{\text {interaction }}>0.05\right)$.

\section{Discussion}

Our study supported that pre-pregnancy overweight and excessive GWG were independently associated with an increased risk of preeclampsia and that the risk might vary by its clinical subtypes. Higher BMI is associated with a risk of preeclampsia in a dose-dependent manner.
The present study also found that the positive association between pre-pregnancy BMI and preeclampsia was similar for S-PE and M-PE, but different for LOPE and EOPE, as pre-pregnancy BMI had a positive association with LOPE but no association with EOPE.

Excessive GWG is associated with an increased risk of preeclampsia. Our study also found that the association between GWG and preeclampsia varied by subtype. We observed an increased risk of M-PE, S-PE, and LOPE, but not EOPE, associated with excessive GWG.

In our study, the highest risk for preeclampsia, S-PE, $\mathrm{M}-\mathrm{PE}$, and LOPE was observed among women who were overweight/obese and had an excessive GWG, although the interactions between pre-pregnancy BMI and GWG were not statistically significant. A potential synergistic effect between pre-pregnancy BMI and GWG warrants further investigation.

The classic concept suggests that preeclampsia is a two-stage disorder [59, 60]. The first stage involves abnormal implantation, including shallow trophoblastic invasion and insufficient spiral artery remodeling or other pathological disorders leading to decreased placental

Table 3 Joint Effects of Pre-pregnancy Maternal BMI and GWG on Preeclampsia and Subtypes in Different Groups (N=9863)

\begin{tabular}{|c|c|c|c|c|c|c|c|}
\hline \multirow[t]{3}{*}{ Pre-pregnancy BMI } & \multicolumn{6}{|c|}{ Weight Gain During Pregnancy (GWG) by IOM Guidelines } & \multirow{3}{*}{$P_{\text {interaction }}$} \\
\hline & \multicolumn{3}{|c|}{ Not Excessive } & \multicolumn{3}{|c|}{ Excessive $^{a}$} & \\
\hline & Cases & Controls & $\mathrm{OR}^{\mathrm{b}}(95 \% \mathrm{Cl})$ & Cases & Controls & $\mathrm{OR}^{\mathrm{b}}(95 \% \mathrm{Cl})$ & \\
\hline Preeclampsia & & & & & & & 0.69 \\
\hline Underweight & 19 & 1234 & $0.75(0.44-1.27)$ & 27 & 824 & $1.65(1.03-2.64)$ & \\
\hline Normal weight & 65 & 3054 & 1.00 & 156 & 3424 & $2.16(1.60-2.92)$ & \\
\hline Overweight/obese & 11 & 219 & $2.10(1.08-4.06)$ & 69 & 761 & $3.78(2.65-5.41)$ & \\
\hline M-PE & & & & & & & 0.87 \\
\hline Underweight & 10 & 1234 & $1.16(0.54-2.49)$ & 14 & 824 & $2.42(1.21-4.84)$ & \\
\hline Normal weight & 21 & 3054 & 1.00 & 65 & 3424 & $2.68(1.62-4.42)$ & \\
\hline Overweight/obese & 2 & 219 & $1.22(0.28-5.27)$ & 29 & 761 & $4.82(2.71-8.59)$ & \\
\hline S-PE & & & & & & & 0.47 \\
\hline Underweight & 9 & 1234 & $0.55(0.26-1.13)$ & 13 & 824 & $1.26(0.66-2.38)$ & \\
\hline Normal weight & 44 & 3054 & 1.00 & 91 & 3424 & $1.94(1.34-2.82)$ & \\
\hline Overweight/obese & 9 & 219 & $2.45(1.17-5.13)$ & 40 & 761 & $3.22(2.06-5.03)$ & \\
\hline EOPE & & & & & & & 0.11 \\
\hline Underweight & 2 & 1234 & $0.51(0.11-2.31)$ & 2 & 824 & $0.81(0.18-3.73)$ & \\
\hline Normal weight & 11 & 3054 & 1.00 & 18 & 3424 & $1.61(0.75-3.45)$ & \\
\hline Overweight/obese & 4 & 219 & $4.48(1.40-14.31)$ & 6 & 761 & $1.97(0.72-5.37)$ & \\
\hline LOPE & & & & & & & 0.80 \\
\hline Underweight & 17 & 1234 & $0.80(0.46-1.40)$ & 25 & 824 & $1.81(1.10-2.97)$ & \\
\hline Normal weight & 54 & 3054 & 1.00 & 138 & 3424 & $2.27(1.64-3.15)$ & \\
\hline Overweight/obese & 7 & 219 & $1.59(0.71-3.56)$ & 63 & 761 & $4.11(2.81-6.03)$ & \\
\hline
\end{tabular}

${ }^{a}$ Excessive weight gain: weight gain above the IOM recommendations, defined as weight gain during pregnancy over $18 \mathrm{~kg}, 16 \mathrm{~kg}$, and $11.5 \mathrm{~kg}$ for underweight, normal weight, and overweight women, respectively

${ }^{\mathrm{b}}$ Adjusted for maternal age, maternal employment during pregnancy, education level, monthly household income, newborn gender, parity, twin status, family history of hypertension 
perfusion. During the second stage, maternal systemic inflammatory response and oxidative stress converge to alter vascular endothelium function, ultimately leading to multi-organ damage [10, 59-62]. The metabolic and biochemical disturbances associated with overweight and obesity may provide the maternal milieu associated with the second stage of preeclampsia [33]. Overweight/obesity, which is considered a chronic inflammatory condition, increases the levels of plasma C-reactive protein and certain inflammatory cytokines [63-65]. This leads to a systemic inflammatory response, resulting in an increase in neutrophils that release toxic compounds (i.e. reactive oxygen species and myeloperoxidase), capable of attacking and destroying vascular endothelium cell integrity. This mechanism ultimately causes the clinical symptoms of preeclampsia [66].

The association between higher BMI and risk of preeclampsia reported in our study is consistent with that of previous studies based on both Western populations [17-21, 23, 26, 28-30, 32-36, 38], and Asian populations $[16,22,24,25,27,31,37,67,68]$. Among the few previous studies that investigated the association between pre-pregnancy BMI and preeclampsia subtypes [14, 19, $30,38]$, their results suggested that overweight/obesity before pregnancy increased the risk of S-PE [14, 19], M-PE [30], LOPE [30, 38], but not EOPE [14, 19, 30, 38]. This finding was supported in our study. The lack of a significant association between pre-pregnancy BMI and EOPE in our study could be due to the small number of EOPE cases $(n=43)$. The consistency of this finding with others suggest that EOPE and LOPE are two different diseases associated with different biochemical markers, risk factors, clinical features, and hemodynamic states [69]. For example, EOPE is typically associated with fetal growth restriction, reduction in placental volume [69], abnormal uterine and umbilical artery Doppler evaluation [70], as well as adverse maternal and neonatal outcomes - maternal mortality is approximately 20 -folds higher for preeclampsia cases that manifest at less than 32 weeks' gestation compared to those that occur at term [71]. In contrast, LOPE often involves normal fetal growth, larger placental volume, normal birth weight and favorable maternal and neonatal outcomes [72].

Our results supported those of previous studies showing that excessive GWG is associated with an increased risk of preeclampsia $[9,30,39-49]$, and contrary to those of other studies $[11,21,50,51]$. Differences in results could be due to the heterogeneity of study designs and methods. Some studies [9, 11, 21, 30, 39, 40, 44, 45] adopted 2009 IOM GWG Guidelines to classify GWG according to pre-pregnancy BMI categories as defined by the WHO, others $[41,42,48,50]$ used the 1990 IOM GWG Guidelines to categorize GWG according to prepregnancy BMI categories based on Metropolitan Life
Insurance Company's weight-for-height standards, and the rest $[43,46,47,49]$ did not use the US IOM GWG Guidelines. In addition to differences in GWG categorization, variations in study population (different ethnic/race distribution) and sources of GWG data (selfreported vs medical record) might also contribute to the inconsistency of the study results.

Previous studies suggested that different preeclampsia subtypes may have different features [69], potentially accounting for varying synergistic effects between prepregnancy BMI and GWG with different preeclampsia subtypes. However, studies on synergistic effect between pre-pregnancy BMI and GWG with preeclampsia are scarce: only two previous studies [13, 49] evaluated the combined effects of pre-pregnancy BMI and GWG on preeclampsia. Both of the studies were based on Western populations, and neither of them examined potential associations with different preeclampsia subtypes. To address the literature gap, our study sought to analyze these joined effects on Asian populations. According to our results, women who were overweight/obese before pregnancy and had an excessive GWG had the highest risk for preeclampsia, S-PE, M-PE, and LOPE. Interestingly, the interaction between pre-pregnancy BMI and GWG was not statistically significant. The potential combined effects of pre-pregnancy BMI and GWG on different preeclampsia subtypes require further investigation.

There were several strengths and limitations to our study. Detailed information on demographic factors, medical histories, and lifestyle factors allowed us to control for important confounding factors. Diagnoses of preeclampsia and its subtypes based on medical records rather than self-reports, minimized potential disease misclassification. In terms of pre-pregnancy weight, such data was self-reported, potentially resulting in unavoidable recall bias. Based on previous literature, pre-gravid overweight/obese women are more likely to underreport pre-pregnancy weight than normal weight women [73]. As information on GWG by trimester was unavailable, we were not able to distinguish between weight gain from adiposity (early weight gain) and that from edema (later weight gain). Previous studies have shown that greater weight gain in early pregnancy led to an elevated risk of future gestational hypertension [74, 75], proposing that adipose tissue rather than edema is part of the etiology of pregnancy-induced hypertension. Further investigations focusing on weight gain trajectory during pregnancy and disease progression are necessary to better understand the effect of pre-pregnancy BMI and GWG on preeclampsia and its subtypes.

\section{Conclusions}

In conclusion, our study results support that prepregnancy overweight (including obesity) and excessive 
GWG are independently associated with an increased risk of preeclampsia and the risk may vary by its clinical subtypes. A potential synergistic effect between prepregnancy BMI and GWG warrants further investigation. Consequently, future preventive strategies are needed to address pre-pregnancy overweight and obesity and to limit gestational weight gain in order to prevent preeclampsia.

\section{Funding}

The study was supported by internal funding from the Gansu Provincial Maternity and Child Care Hospital, Gansu Provincial Science and Technology Department Grant (1204WCGA021) and the National Institutes of Health Grants (K02HD70324, R01ES016317, and R01ES019587). The funding bodies did not play any role in study design, data collection, data analysis, data interpretation, or writing and revising of the manuscript.

\section{Availability of data and materials}

The study data could be provided on the request from co-authors.

\section{Authors' contributions}

$\mathrm{JQ}, \mathrm{QL}$, and $\mathrm{YZ}$ designed the research; $\mathrm{YS}, \mathrm{HH}, \mathrm{BM}, \mathrm{WD}, \mathrm{XH}, \mathrm{HC}, \mathrm{XL}, \mathrm{LL}, \mathrm{ZT}, \mathrm{SX}$ $M Z, X X$, and WQ performed statistical analysis. $Y S, J Q, N Z, D W$, and $Y Z$ collected data and drafted the manuscript. All authors contributed to the final draft and approved the manuscript.

\section{Ethics approval and consent to participate}

The current study is approved by the Human Investigation Committees at the Gansu Provincial Maternity and Child Care Hospital and Yale University. All participants had written consent before recruit in this study.

\section{Consent for publication}

Not applicable.

\section{Competing interests}

The authors declare that they have no competing interests.

\section{Publisher's Note}

Springer Nature remains neutral with regard to jurisdictional claims in published maps and institutional affiliations.

\section{Author details}

'Gansu Provincial Maternity and Child Care Hospital, 143 North Road, Qilihe District, Lanzhou, Gansu Province 730050, China. ${ }^{2}$ Yale University School of Public Health, 60 College Street, New Haven, CT 06520, USA. ${ }^{3}$ Yale School of Medicine, New Haven, CT, USA

\section{Received: 21 November 2016 Accepted: 6 November 2017}

Published online: 01 December 2017

\section{References}

1. Hutcheon JA, Lisonkova S, Joseph KS. Epidemiology of pre-eclampsia and the other hypertensive disorders of pregnancy. Best prac res Clin obstet gynaecol. 2011;25(4):391-403.

2. Lenfant C. National Education Program Working Group on high blood pressure in pregnancy: working group report on high blood pressure in pregnancy. J Clin Hypertens (Greenwich). 2001;3(2):75-88.

3. Roberts JM, Cooper DW. Pathogenesis and genetics of pre-eclampsia. Lancet. 2001;357(9249):53-6.

4. Redman CW, Sargent IL: Latest advances in understanding preeclampsia. Science 2005, (308(5728)):1592-1594

5. Xiao R, Sorensen TK, Williams MA, Luthy DA. Influence of pre-eclampsia on fetal growth. The journal of maternal-fetal \& neonatal medicine : the official journal of the European Association of Perinatal Medicine, the Federation of Asia and Oceania Perinatal Societies. Int Perinatal Obstet. 2003;13(3):157-62.

6. Roberts JM, Pearson G, Cutler J, Lindheimer M. Pregnancy NWGoRoHD: summary of the NHLBI working group on research on hypertension during pregnancy. Hypertension. 2003;41(3):437-45.
7. Porreco RP, Barkey R. Peripartum intensive care. The journal of maternalfetal \& neonatal medicine : the official journal of the European Association of Perinatal Medicine, the Federation of Asia and Oceania Perinatal societies. Int Perinatal Obstet. 2010;23(10):1136-8.

8. Irgens HU, Reisaeter L, Irgens LM, Lie RT. Long term mortality of mothers and fathers after preeclampsia population based cohort study. BMJ. 2001; 323(7323):1213-7.

9. Haugen M, Brantsaeter AL, Winkvist A, Lissner L, Alexander J, Oftedal B, Magnus $P$, Meltzer HM. Associations of pre-pregnancy body mass index and gestational weight gain with pregnancy outcome and postpartum weight retention: a prospective observational cohort study. Bmc Pregnancy and Childbirth. 2014;14

10. Jeyabalan A. Epidemiology of preeclampsia: impact of obesity. Nutr Rev. 2013;71(Suppl 1):S18-25.

11. O'Dwyer V, O'Toole F, Darcy S, Farah N, Kennelly MM, Turner MJ. Maternal obesity and gestational weight gain. J obstet gynaecol: J Inst of Obstet Gynaecol. 2013;33(7):671-4.

12. Swank ML, Caughey AB, Farineli CK, Main EK, Melsop KA, Gilbert WM, Chung $\mathrm{JH}$. The impact of change in pregnancy body mass index on the development of gestational hypertensive disorders. J Perinatol. 2014;34(3):181-5.

13. Barton JR, Joy SD, Rhea DJ, Sibai AJ, Sibai BM. The influence of gestational weight gain on the development of gestational hypertension in obese women. Am J Perinatol. 2015;32(7):615-9.

14. Ornaghi S, Tyurmorezova A, Algeri P, Giardini V, Ceruti P, Vertemati E, Vergani P. Influencing factors for late-onset preeclampsia. J Matern-Fetal Neonatal Med. 2013:26(13):1299-302.

15. Redman CWG, Sacks GP, Sargent IL. Preeclampsia: an excessive maternal inflammatory response to pregnancy. Am J Obstet Gynecol. 1999;180(2): 499-506.

16. Wei YM, Yang HX, Zhu WW, Liu XY, Meng WY, Wang YQ, Shang LX, Cai $Z Y$, Ji LP, Wang YF, et al. Risk of adverse pregnancy outcomes stratified for pre-pregnancy body mass index. J Matern Fetal Neonatal Med. 2015:1-5.

17. Vinturache A, Moledina N, McDonald S, Slater D, Tough S. Pre-pregnancy body mass index (BMI) and delivery outcomes in a Canadian population. BMC Pregnancy Childbirth. 2014:14:422.

18. Fox NS, Roman AS, Saltzman DH, Klauser CK, Rebarber A. Obesity and adverse pregnancy outcomes in twin pregnancies. J Matern Fetal Neonatal Med. 2014;27(4):355-9.

19. Pare E, Parry S, McElrath TF, Pucci D, Newton A, Lim KH. Clinical risk factors for preeclampsia in the 21st century. Obstet Gynecol. 2014;124(4):763-70.

20. Magann EF, Doherty DA, Sandlin AT, Chauhan SP, Morrison JC. The effects of an increasing gradient of maternal obesity on pregnancy outcomes. Aust N Z J Obstet Gynaecol. 2013;53(3):250-7.

21. Gaillard R, Durmus B, Hofman A, Mackenbach JP, Steegers EAP, Jaddoe WW. Risk factors and outcomes of maternal obesity and excessive weight gain during pregnancy. Obesity. 2013;21(5):1046-55.

22. Tsai IH, Chen CP, Sun FJ, Wu CH, Yeh SL. Associations of the pre-pregnancy body mass index and gestational weight gain with pregnancy outcomes in Taiwanese women. Asia Pac J Clin Nutr. 2012;21(1):82-7.

23. Persson M, Pasupathy D, Hanson U, Westgren M, Norman M. Pre-pregnancy body mass index and the risk of adverse outcome in type 1 diabetic pregnancies: a population-based cohort study. BMJ Open. 2012;2(1):e000601.

24. Liu X, Du J, Wang G, Chen Z, Wang W, Xi Q. Effect of pre-pregnancy body mass index on adverse pregnancy outcome in north of China. Arch Gynecol Obstet. 2011;283(1):65-70.

25. Chen Z, Du J, Shao L, Zheng L, Wu M, Ai M, Zhang Y. Prepregnancy body mass index, gestational weight gain, and pregnancy outcomes in China. Int J Gynaecol Obstet. 2010;109(1):41-4.

26. Stone CD, Diallo O, Shyken J, Leet T. The combined effect of maternal smoking and obesity on the risk of preeclampsia. J Perinat Med. 2007;35(1):28-31.

27. Khader $Y$, Jibreal $M$, Burgan $S$, Amarin Z. Risk indicators of pre-eclampsia in north Jordan: is dental caries involved? Gynecol Obstet Investig. 2007;63(4):181-7.

28. Doherty DA, Magann EF, Francis J, Morrison JC, Newnham JP. Prepregnancy body mass index and pregnancy outcomes. Int J Gynaecol Obstet. 2006;95(3):242-7.

29. Arbour NC, Lorenz E, Schutte BC, Zabner J, Kline JN, Jones M, Frees K, Watt $J$ L, Schwartz DA. TLR4 mutations are associated with endotoxin hyporesponsiveness in humans. Nat Genet. 2000;25(2):187-91.

30. Baker AM, Haeri S. Estimating risk factors for development of preeclampsia in teen mothers. Arch Gynecol Obstet. 2012;286(5):1093-6. 
31. Nanjundan P, Bagga R, Kalra JK, Thakur JS, Raveendran A. Risk factors for early onset severe pre-eclampsia and eclampsia among north Indian women. J Obstet Gynaecol. 2011;31(5):384-9.

32. O'Brien TE, Ray JG, Chan WS. Maternal body mass index and the risk of preeclampsia: a systematic overview. Epidemiology. 2003;14(3):368-74.

33. Bodnar LM, Ness RB, Markovic N, Roberts JM. The risk of preeclampsia rises with increasing prepregnancy body mass index. Ann Epidemiol. 2005;15(7):475-82.

34. Catov JM, Ness RB, Kip KE, Olsen J. Risk of early or severe preeclampsia related to pre-existing conditions. Int J Epidemiol. 2007;36(2):412-9.

35. Sibai BM, Ewell M, Levine RJ, Klebanoff MA, Esterlitz J, Catalano PM, Goldenberg RL, Joffe G. Risk factors associated with preeclampsia in healthy nulliparous women. Am J Obstet Gynecol. 1997;177(5):1003-10.

36. Baeten JM, Bukusi EA, Lambe M. Pregnancy complications and outcomes among overweight and obese nulliparous women. Am J Public Health. 2001;91(3):436-40.

37. Leung TY, Leung TN, Sahota DS, Chan OK, Chan LW, Fung TY, Lau TK. Trends in maternal obesity and associated risks of adverse pregnancy outcomes in a population of Chinese women. Bjog-an Int J Obstet Gynaecol. 2008;115(12):1529-37.

38. Fang R, Dawson A, Lohsoonthorn V, Williams M. Risk factors of early and late onset preeclampsia among Thai women. Asian Biomed (Res Rev News). 2009;3(5):477-186.

39. Swank ML, Marshall NE, Caughey AB, Main EK, Gilbert WM, Melsop KA, Chung $\mathrm{JH}$. Pregnancy outcomes in the super obese, stratified by weight gain above and below Institute of Medicine Guidelines. Obstet Gynecol. 2014;124(6):1105-10.

40. Truong YN, Yee LM, Caughey AB, Cheng YW. Weight gain in pregnancy: does the Institute of Medicine have it right? Am J Obstet Gynecol. 2015; 212(3):362.e1-8.

41. DeVader SR, Neeley HL, Myles TD, Leet TL. Evaluation of gestational weight gain guidelines for women with normal prepregnancy body mass index. Obstet Gynecol. 2007;110(4):745-51.

42. Flick AA, Brookfield KF, de la Torre L, Tudela CM, Duthely L, GonzalezQuintero VH. Excessive weight gain among obese women and pregnancy outcomes. Am J Perinatol. 2010;27(4):333-8.

43. Aksornphusitaphong A, Phupong V. Risk factors of early and late onset preeclampsia. J Obstet Gynaecol Res. 2013:39(3):627-31.

44. Harper LM, Tita A, Biggio JR. The Institute of Medicine Guidelines for gestational weight gain after a diagnosis of gestational diabetes and pregnancy outcomes. Am J Perinatol. 2015;32(3):239-45.

45. Liu L, Hong Z, Zhang L. Associations of prepregnancy body mass index and gestational weight gain with pregnancy outcomes in nulliparous women delivering single live babies. Sci Rep. 2015;5:12863.

46. Gavard JA, Artal R. GestationalWeight gain and maternal and neonatal outcomes in term twin pregnancies in ObeseWomen. Twin Res Hum Genet. 2014;17(2):127-33.

47. Tabatabaei M. Gestational weight gain, prepregnancy body mass index related to pregnancy outcomes in KAZERUN, FARS, IRAN. J oprenatal med. 2011;5(2):35-40.

48. Langford A, Joshu C, Chang JJ, Myles T, Leet T. Does gestational weight gain affect the risk of adverse maternal and infant outcomes in overweight women? Matern Child Health J. 2011:15(7):860-5.

49. Cedergren M. Effects of gestational weight gain and body mass index on obstetric outcome in Sweden. Int J Gynecol Obstet. 2006:93(3):269-74.

50. Shirazian T, Monteith S, Friedman F, Rebarber A. Lifestyle modification program decreases pregnancy weight gain in obese women. Am J Perinatol. 2010;27(5):411-4

51. Tanentsapf I, Heitmann BL, Adegboye AR. Systematic review of clinical trials on dietary interventions to prevent excessive weight gain during pregnancy among normal weight, overweight and obese women. BMC Pregnancy Childbirth. 2011;11:81.

52. Mbah AK, Kornosky JL, Kristensen S, August EM, Alio AP, Marty PJ, Belogolovkin V, Bruder K, Salihu HM. Super-obesity and risk for early and late pre-eclampsia. BJOG. 2010;117(8):997-1004.

53. Chandrasekaran S, Levine LD, Durnwald CP, Elovitz MA, Srinivas SK. Excessive weight gain and hypertensive disorders of pregnancy in the obese patient. J Matern Fetal Neonatal Med. 2015;28(8):964-8.

54. Wang Y, Zhao N, Qiu J, He X, Zhou M, Cui H, LV L, Lin X, Zhang C, Zhang H, et al. Folic acid supplementation and dietary folate intake, and risk of preeclampsia. Eur J Clin Nutr. 2015;69(10):1145-50.
55. Qiu J, He X, Cui H, Zhang C, Zhang H, Dang Y, Han X, Chen Y, Tang Z, Zhang $\mathrm{H}$, et al. Passive smoking and preterm birth in urban China. Am J Epidemiol. 2014;180(1):94-102.

56. Wang J, Thornton J, Russell M, Burastero S. S H, Jr PR: Asians have lower body mass index but higher percent body fat than do whites comparions of anthropometric measurements. Am J Clin Nutr. 1994;60(1):23-8.

57. Zhou B. Cooperative meta-analysis Group of the Working Group on obesity in China: predictive values of body mass index and waist circumference for risk factors of certain related diseases in Chinese adults-study on optimal cut-off points of body mass index and waist circumference in Chinese adults. Asia Pac J Clin Nutr. 2002;11(Suppl):S685-93.

58. Medicine lo: Weight gain during pregnancy: reexamining the guidelines. 2009.

59. Ness RB, Roberts JM. Heterogeneous causes constituting the single syndrome of preeclampsia: a hypothesis and its implications. Am J Obstet Gynecol. 1996;175(5):1360-70.

60. Roberts JM, Hubel CA. Is oxidative stress the link in the two-stage model of pre-eclampsia? Lancet. 1999;354(9181):788-9.

61. Roberts JM, Bodnar LM, Patrick TE, Powers RW. The role of obesity in preeclampsia. Pregnancy Hypertens. 2011;1(1):6-16.

62. Metzger BE, Lowe LP, Dyer AR, Trimble ER, Sheridan B, Hod M, Chen R, Yogev Y, Coustan DR, Catalano PM, et al. Hyperglycemia and adverse pregnancy outcome (HAPO) study associations with neonatal anthropometrics. Diabetes. 2009;58(2):453-9.

63. Esposito K, Nicoletti G. Giugliano D: cytokines and endothelial dysfunction a link for the raised cardiovascular risk associated with visceral obesity. J Endocrinol Investig. 2002;25(7):646-9.

64. Ziccardi P. Reduction of inflammatory cytokine concentrations and improvement of endothelial functions in obese women after weight loss over one year. Circulation. 2002;105(7):804-9.

65. Straczkowski M, Dzienis-Straczkowska S, Stepien A, Kowalska I, Szelachowska $M$, Kinalska I. Plasma interleukin-8 concentrations are increased in obese subjects and related to fat mass and tumor necrosis factor-alpha system. $J$ Clin Endocrinol Metab. 2002:87(10):4602-6.

66. Walsh SW. Obesity: a risk factor for preeclampsia. Trends Endocrinol Metab. 2007:18(10):365-70.

67. Tanaka T, Ashihara K, Nakamura M, Kanda T, Fujita D, Yamashita Y, Terai Y, Kamegai $\mathrm{H}$, Ohmichi M. Associations between the pre-pregnancy body mass index and gestational weight gain with pregnancy outcomes in Japanese women. J Obstet Gynaecol Res. 2014:40(5):1296-303.

68. Kazemian E, Sotoudeh G, Dorosty-Motlagh AR, Eshraghian MR, Bagheri M. Maternal obesity and energy intake as risk factors of pregnancy-induced hypertension among Iranian women. J Health Popul Nutri. 2014;32(3):486-93.

69. Raymond D, Peterson E. A critical review of early-onset and late-onset preeclampsia. Obstet Gynecol Surv. 2011:66(8):497-506.

70. Crispi F, Llurba E, Dominguez C, Martin-Gallan P, Cabero L, Gratacos E. Predictive value of angiogenic factors and uterine artery Doppler for earlyversus late-onset pre-eclampsia and intrauterine growth restriction. Ultrasound Obstet Gynecol. 2008:31(3):303-9.

71. MacKay AP, Berg CJ, Atrash HK. Pregnancy-related mortality from preeclampsia and eclampsia. Obstet Gynecol. 2001;97(4):533-8.

72. Obed S, Patience A. Birth weight and ponderal index in pre-eclampsia: a comparative study. Ghana Med J. 2006;40(1):8-13.

73. Mandujano A, Huston-Presley L, Waters TP, Catalano PM. Women's reported weight: is there a discrepancy? J Matern Fetal Neonatal Med. 2012;25(8):1395-8.

74. Macdonald-Wallis C, Tilling K, Fraser A, Nelson SM, Lawlor DA. Gestational weight gain as a risk factor for hypertensive disorders of pregnancy. Am J Obstet Gynecol. 2013;209(4):327 e1-317.

75. Zhou A, Xiong C, Hu R, Zhang Y, Bassig BA, Triche E, Yang S, Qiu L, Zhang Y, Yao C, et al. Pre-Pregnancy BMI, Gestational Weight Gain, and the Risk of Hypertensive Disorders of Pregnancy: A Cohort Study in Wuhan, China. PLoS One. 2015;10(8):e0136291. 